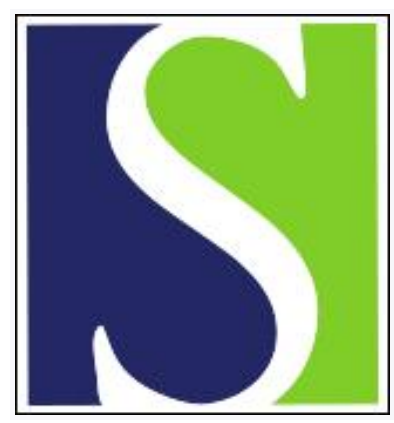

Scand J Work Environ Health 2015;41(3):223-233

https://doi.org/10.5271/sjweh.3489

Published online: 06 Mar 2015, Issue date: 01 May 2015

Results of a feasibility study: barriers and facilitators in implementing the Sherbrooke model in France

by Fassier J-B, Durand M-J, Caillard J-F, Roquelaure Y, Loisel P

Work disability prevention interventions are complex innovations competing against usual care, workplace habits, and social insurance systems' complexity. The trial effectiveness of these interventions does not guarantee their implementation and sustainability. Multilevel barriers in the healthcare, workplace and insurance systems must be identified and tackled, and implementation strategies must be evaluated to monitor the implementation process and fidelity.

Affiliation: UMRESTTE, joint unit INRETS/UCBL/InVS, Université de Lyon; Université Claude Bernard Lyon 1, Domaine Rockefeller, 69373 Lyon Cedex 08, France. jean-baptiste.fassier@univ-lyon1.fr

Refers to the following texts of the Journal: 2005;31(3):191-204 2011;37(2):99-108

The following article refers to this text: 2015;41(3):219-221

Key terms: barrier; disability; facilitator; feasibility study; France; low-back pain; return to work; return-to-work intervention; RTW; Sherbrooke model; sick leave; sickness absence

This article in PubMed: www.ncbi.nlm.nih.gov/pubmed/25743881

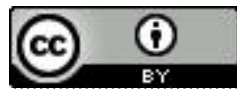




\title{
Results of a feasibility study: barriers and facilitators in implementing the Sherbrooke model in France
}

\author{
by Jean-Baptiste Fassier, MD, PhD, 1, 2, 3 Marie-José Durand, PhD, ${ }^{3}$ Jean-François Caillard, MD, ${ }^{4}$ Yves \\ Roquelaure, $M D$, PhD, ${ }^{5}$ Patrick Loisel, $M D^{6}$
}

\begin{abstract}
Fassier J-B, Durand M-J, Caillard J-F, Roquelaure Y, Loisel P. Results of a feasibility study: barriers and facilitators in implementing the Sherbrooke model in France. Scand J Work Environ Health. 2015;41(3):223-233. doi:10.5271/sjweh.3489
\end{abstract}

Objectives Return-to-work interventions associated with the workplace environment are often more effective than conventional care. The Sherbrooke model is an integrated intervention that has proved successful in preventing work disability due to low-back pain. Implementation, however, runs up against many obstacles, and failure has been reported in many countries. The present study sought to identify barriers to and facilitators of the implementation of the Sherbrooke model within the French health system.

Methods A multiple case study with nested levels of analysis was performed in two regions of France. A conceptual framework was designed and refined to identify barriers and facilitators at the individual, organizational and contextual levels. Qualitative data were collected via semi-structured interview $(\mathrm{N}=22)$, focus groups $(\mathrm{N}=7)$, and observation and from the gray literature. Participants $(\mathrm{N}=61)$ belonged to three fields: healthcare, social insurance, and the workplace.

Results Numerous barriers and facilitators were identified in each field and at each level, some specific and others common to workers in all fields. Individual and organizational barriers comprised lack of time and resources, discordant professional values, and perceived risk. Legal barriers comprised medical confidentiality, legal complexity, and priority given to primary prevention. Individual-level facilitators comprised needs and perceived benefits. Some organizations had concordant values and practices. Legal facilitators comprised possibilities of collaboration and gradual return to work.

Conclusion The present feasibility analysis of implementing the Sherbrooke model revealed numerous barriers and facilitators suggesting a new implementation strategy be drawn up if failure is to be avoided.

Key terms disability; low-back pain; return to work; return-to-work intervention; RTW; sick leave; sickness absence.

The aging of the working population and intensification of work are structural trends tending to increase the incidence of musculoskeletal pain and disability (1). Interventions in the workplace have been developed to facilitate return to and maintenance of work (2). The Sherbrooke model has proved more effective than conventional care in facilitating return to work (RTW) after low-back-pain disability (3). It is characterized by its early time frame (four weeks of work absence), and its change of paradigm in rehabilitation. Its first component is not a medical but a participatory ergonomic intervention in the workplace to facilitate work accommodation and the RTW of the worker with low-back pain. Its second step is implemented only if necessary after 12 weeks of work absence, with the so-called "therapeutic" approach with a progressive and adapted RTW under the supervision of a facilitator (ergonomist or occupational therapist) (4). Despite demonstrations of its good internal

1 UMRESTTE, joint unit INRETS/UCBL/InVS, Université de Lyon; Université Claude Bernard Lyon 1, Domaine Rockefeller, Lyon, France.

2 Hospices Civils de Lyon, Service de Médecine et Santé au Travail, Centre Hospitalier Lyon Sud, Pierre Bénite, France.

3 CAPRIT, School of Rehabilitation, Université de Sherbrooke, Québec, Canada.

4 Service des Maladies Professionnelles, CHU de Rouen, France.

5 Service des Maladies Professionnelles, CHU d'Angers, France.

6 Dalla Lana School of Public Health, University of Toronto, Ontario, Canada.

Correspondence to: Dr Jean-Baptiste Fassier, UMRESTTE, Domaine Rockefeller, 69373 Lyon Cedex 08, France. [E-mail: jean-baptiste. fassier@univ-lyon1.fr] 
validity and cost-effectiveness (5) and an implementation plan (6), the model failed to be included in the healthcare system in Québec (7). Other failures of implementation and sustainability of work disability prevention interventions have been reported (7).

Work disability prevention interventions show all the criteria of complex health interventions (8). They require change in representations and behavior at different levels in categories of agents with conflicting interests (7). Designing RTW programs in the form of such complex interventions requires careful attention to conditions of implementation and their sustainability beyond the clinical trial stage, which assesses efficacy in experimental conditions (9).

It has been found that the spread of innovations and the implementation of health programs run up against many barriers at the individual, organizational, and contextual (economic, legal, political, social and cultural) level $(9,10)$. For this reason, it has been recommended that the context in which a new intervention is to be implemented be analyzed and barriers and facilitators be identified in order to guide strategy (9). However, there is no clear indication as to how these barriers and facilitators should be identified (11).

In France, reducing low-back pain disability has been made a public health priority. A scientific task force on low-back pain recommended the assessment of the Sherbrooke therapeutic RTW approach (12), and the Workers Compensation Board (Assurance Maladie, Direction des Risques Professionnels) funded a research project to evaluate the feasibility of the Sherbrooke model in France. This study was deemed necessary due to some characteristics of the French context which contrast with the Sherbrooke model, namely an over-medicalization of low-back pain and the predominance of a hospital-based approach to rehabilitation (13). Therefore, a specific conceptual framework was developed to analyze the feasibility of a RTW intervention for workers with low-back pain (14). Using this framework, the present study sought to identify barriers and facilitators in implementing the Sherbrooke model in two regions of the French health system at individual, organizational and contextual levels for three categories of agent: workplace actors, healthcare professionals, and health insurance agents.

\section{Methods}

A multiple case study with nested levels of analysis was performed (15). This method of qualitative research is commonly used in health service research (16). The cases were two geographical health system regions; the analysis levels were individuals, organizations, and general contexts.

\section{Participant sampling}

Two regions of France were selected for their high prevalence of musculoskeletal disorders. In each one, a theoretical sampling strategy (17) was drawn up based on the categories of the "arena" model in work disability prevention (7). First, purposeful sampling included three key informants per region for each category of actor. Then snowball sampling per region identified participants in each category. Table 1 presents participant characteristics and the means of data gathering.

\section{Data collection}

The participants were involved in a structured transfer of knowledge of Sherbrooke model theory and practice. After this 3-hour training session, data were collected by semi-structured individual interview $(\mathrm{N}=22)$ and focus groups $(\mathrm{N}=7)$ led by an investigator. Focus groups were homogeneous in terms of background and occupation with no primary intention to explore divergences or reach consensus among the participants. The questions were based on the conceptual framework (14) and concerned perceived needs for a Sherbrooke-type intervention, perceived difficulties of understanding and use, perceived pros and cons, perceived usefulness, and compatibility with the participants' values and practices. In two rehabilitation centers, triangulation of data collection modes was used to improve accuracy. Participant observation (inclusion of low-back pain patients in functional restoration programs) provided a description of individual and organizational practices. Gray literature (annual activity reports, internal procedures) was used to triangulate these observations and participants' responses. The questions used with each data collection mode were the same: who does what, how, when, where and why? The findings obtained by these different means were concordent.

\section{Study context}

Data were collected in two rehabilitation centers, two national health insurance offices, three occupational health services, and four workplaces with high rates of absenteeism for low-back pain (a car maker, one association providing home services for the dependent, and two university hospitals). Data collection was performed between March 2006 and May 2007.

\section{Data analysis}

All interviews and focus group meetings were recorded, transcribed, and collated in a single database. Mean interview time was 59 minutes (range, 22-180 minutes). The ATLAS.ti v5.2 (Berlin) thematic qualitative content 
Table 1. Respondent characteristics per region. Some respondents were involved in both the interview and focus group. [ER=employer;

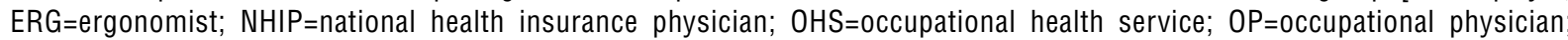
OT=occupational therapist; PT=physical therapist; SW=social worker.]

\begin{tabular}{|c|c|c|c|}
\hline & \multicolumn{3}{|c|}{ Interviews and focus groups (FG) } \\
\hline & Healthcare professionals & Insurance system & Workplaces \\
\hline Case (region) 1 & PT (2); OT (1); OP (3) & $\begin{array}{l}\text { FG1: Regional prevention department management } \\
\text { (2); Regional social department management (2) } \\
\text { FG2: NHIP (5) }\end{array}$ & $\begin{array}{l}\text { ER (1); ERG (2) } \\
\text { FG1: ER (1); manager (1); worker (1) } \\
\text { FG2: OP (2); ERG (2) }\end{array}$ \\
\hline Case (region) 2 & $\begin{array}{l}\text { OP (2); rehabilitation physician (1) } \\
\text { FG1 (OHS1): OP (5) } \\
\text { FG2 (OHS2): OP (10) }\end{array}$ & $\begin{array}{l}\text { SW (2); NHIP (2); Regional prevention department } \\
\text { management (1) }\end{array}$ & $\begin{array}{l}\text { ER (1); unions (2); ERG (1); labor } \\
\text { administration (1) } \\
\text { ER (1); union (1); OP (4) } \\
\text { ERG (1); SW (3); psychologist (1) }\end{array}$ \\
\hline
\end{tabular}

analysis software was used to analyze and compare content from each region (15). Coding reliability was checked by a second investigator using co-coding, and disagreements were resolved by discussion. The eight dimensions of the initial conceptual framework were used as core categories of analysis in a deductive fashion. Some categories were modified and/or refined in an inductive way (such as "top and frontline management" included in organizational practices) so as to be able to take into account all the data. The rationale for the modifications and the final conceptual framework are detailed in a previous publication (14). Analytical categories were deemed saturated when further interviews provided no new input.

For accuracy considerations, a preliminary report was sent to the participants who were requested to precise, correct, or confirm its content as far as necessary. Eight participants answered they had no comment. Four participants had minor changes. No disagreement was expressed. All answers were appended to the final research report.

The principal investigator kept a log-book during the research project. Pro-innovation biases favoring the Sherbrooke model were identified and taken into account to analyze discordant values expressed by some respondents.

The research review board of Charles LeMoyne Hospital, Longueuil, Quebec, approved the research protocol. All participants signed an informed consent form.

\section{Results}

\section{Healthcare system (table 2)}

External context: barriers. At the legal level, medical confidentiality was identified as a barrier to collaboration between general practitioners (GP), national health insurance physicians (NHIP) and occupational physicians
(OP). GP cited the complexity of administrative procedures as discouraging. The "payment by act" system was seen as a source of over-medicalization (table 2).

External context: facilitators. At the legal level, one facilitator was the possibility of structuring care in a network associating primary/secondary care, public/ private sector and occupational medicine/rehabilitation. Certain legal provisions allow gradual RTW, in line with the Sherbrooke model.

Organizations (rehabilitation center, occupational medicine department, community physician): barriers. Lack of interest in RTW on the part of certain rehabilitation structures and GP was cited as a barrier, with treatment objectives unrelated to work. Lack of human and financial resources to enable workplace interventions was highlighted. Lack of structured collaboration was another barrier, whether between healthcare professionals or with other sectors (workplace, health insurance).

Organizations: facilitators. An organizational culture integrating work disability prevention was identified as a facilitator, as was a policy of screening at the sub-acute low-back pain stage with resources allocated for workplace intervention (ergonomist). Certain rehabilitation centers set up collaborations with occupational health services and community physiotherapists.

Individuals (health professional, patient): barriers. Physicians' lack of knowledge of work and the relevant legislation was clearly identified as a barrier. A strictly biomedical vision of low-back pain was associated with objectives centered on cure without concern for RTW. Some practices amounted to over-medicalization, with lack of collaboration and mutual distrust between physicians. Healthcare professionals' reticence regarding movement was identified as a barrier. Finally, overwork and lack of time were unanimously cited as a barrier to involvement in this type of model. 
Table 2. Barriers and facilitators in the healthcare system. [GL=gray literature; $G P=$ general practitioner; $L E=$ legislation; $O B=0 b s e r v a t i o n ;$ $\mathrm{RTW}=$ return to work; SV=stakeholder views.] Content in italic font refers to the data collected.

\begin{tabular}{ll}
\hline Level & Barriers \\
\hline External: legal, economic or political context \\
Legal issues & Medical confidentiality (LE+SV) \\
& Complexity of procedures and form-filling (SV) \\
& "The GPs know what low back pain is. Now, who \\
& should they alert? And would they? Because of medical \\
& secrecy, that is a stumbling block, to my \\
& opinion."(Workplace ergonomist) \\
& "Doing paperwork and so on. It's not our culture, it's not \\
& paid at all, it's extremely time-consuming. Yes, all GPs say \\
& that." (Occupational physician, regional labor inspectorate) \\
& Fee-for-service reimbursement basis (LE+SV) \\
"And doctors in private practice in our country ... consult \\
every quarter of an hour, get paid the fees for a quarter \\
of an hour, then go on to the next one." (President of an \\
occupational health service)
\end{tabular}

Organizational: internal context of a hospital, private practice, rehabilitation or occupational health service

Organizational culture Lack of interest in work disability $(\mathrm{SV}+\mathrm{OB}+\mathrm{GL})$

"(...) in the spinal functional rehabilitation sessions we do here, there is not much, really not much connection with the workplace." (Occupational therapist in a rehabilitation center)

Target population and Focus on physiological outcomes; No interest in

/ or goal setting occupational outcomes; Focus on chronic pain patients $(\mathrm{SV}+\mathrm{OB}+\mathrm{GL})$

"Well for us, the problem we have is referral... It's late... The folk who come for effort training tend to come at the end of the process." (Ergonomist in a rehabilitation center)

Resources

Lack of resources to intervene in the workplace $(\mathrm{SV}+\mathrm{OB}+\mathrm{GL})$

"The health insurance said: "We pay for health. In the workplace, the employers should pay". It is not absurd, for an insurer." (Occupational physician)

Collaborations

Lack of structured collaborations within and outside healthcare (SV)

"How can we get all the stakeholders on board so as to put the model in place? (...) Given the different failures we had, each one working alone? (Occupational physician, regional labor inspectorate)

Individual: healthcare practitioner (HCP), patient

Knowledge and skills Lack of knowledge about workplace issues or legal issues (SV)

"You have some doctors who have no technical culture, they don't have a clue about ergonomics, (...) a lot of them" (Occupational physician)

Biomedical view of low back pain; Fear of movement (SV+GL)

"Physiotherapists are afraid to mobilize their patients because of pain." (Physiotherapist)

Values

Lack of interest in work disability (SV)

"For GPs who don't have a social streak, it's no use." (Occupational physician, regional labor inspectorate)

Lack of agreement with RTW objectives (SV)

"The worker can feel the pressure for RTW, whatever the cost." (Personnel occupational psychologist, University Hospital)

Practice

Practice discordant with clinical guidelines $(\mathrm{SV}+\mathrm{GL})$

"You know, they do always the same things... heat... holy massages... that kind of therapies that don't work." (Physiotherapist)
Facilitators

Possibility of structured healthcare networks ( $\mathrm{LE}+\mathrm{OB}+\mathrm{GL})$

Legislation pertaining to return to work, work rehabilitation and accommodation (LE)

Public health legislation

Developed interest in work disability prevention or return to work issues $(\mathrm{SV}+\mathrm{OB}+\mathrm{GL})$

Objectives, procedures and reports of rehabilitation centres and networks ("Lombaction" regional network, "Comète-France" national network)

Formal policy and measures to identify the target population at the subacute phase $(G \mathrm{~L})$

"Lombaction" regional network

Allocation of specific human and financial resources to intervene in the workplace $(\mathrm{SV}+\mathrm{OB}+\mathrm{GL})$

Ergonomist financed in rehabilitation teams by the "Comète-France" national network

Establishment of structured collaborations $(\mathrm{SV}+\mathrm{OB}+\mathrm{GL})$

"Lombaction" regional network, "Comète-France" national network "With our interdisciplinary team, we get much help from the ergonomist, the social workers, and so on..." (Occupational physician)

Accurate knowledge about workplace issues or legal issues (SV) "I think the OP is able to implement such a strategy, because he knows about collective health, occupational health. (..) He can tell the employer how many work-related musculoskeletal disorders there are." (Ergonomist)

Biopsychosocial view of low back pain (SV)

"For GPS who have a social streak, a political one, in the noble sense, then, it works." (Occupational physician, regional labor inspectorate)

Professional role conceived with a social role (SV)

"I feel right in my professional role within this model" (Occupational physician)

Agreement with RTW objectives (SV)

"The role of occupational physicians should increasingly be to help keep employees at work or encourage their capacity to work." (Occupational physician)

Practice concordant with clinical guidelines (SV)

"Reassure and reactivate, well, that's what I do!" (Physiotherapist) 
Table 2. continued

\begin{tabular}{lll}
\hline Level & Barriers & Facilitators \\
\hline Resources & No collaboration; distrust (SV+GL) & Collaborative practice; trust (SV+GL) \\
& Work overload / Lack of time (SV+GL) & \\
& "We are stuck with medical time issues (...). They should \\
& be able to spend 3 days with a case, and to see no one else \\
& during 3 days. (...) As long as they must see every one... \\
& and do everything... at the same time.... We can't make \\
& it..."(Occupational physician) \\
\hline
\end{tabular}

Individuals: facilitators. Conversely, some healthcare professionals had a clear understanding of the legal bases and issues in RTW. They had a biopsychosocial vision of low-back pain. Their perception of their professional role included the social dimension over and above healthcare as such. These people were more used to teamwork with others.

\section{National health insurance system (table 3)}

External context: barriers. Respondents working in the national health insurance system itself underlined the complexity of health insurance law as a barrier. Legal barriers to sharing personal data were cited as a barrier to identifying workers at the sub-acute phase. The priority given in the legislation to primary prevention was seen as a barrier to developing solutions in tertiary prevention. Economically, limitations of health expenditure were cited as a barrier.

External context: facilitators. Health insurance procedures for accompanying workers on sick leave for $>3$ months were identified as a possible facilitator, as was the legislation on therapeutic part-time work.

Organizations (health insurance agencies): barriers. The priority given to workers on $>6$ months' sick leave was cited as a barrier to early interventions. Lack of resources to develop more interventions was underlined. Fear or refusal of increased rehabilitation expenditure was reported as hindering the development of ergonomic intervention in favor of RTW. Some health insurance agencies showed a lack of collaboration between departments: administrative, medical and social.

Organizations: facilitators. Dedicated procedures for identifying low-back pain patients as of 3-months' sick leave were seen as a facilitator in some national health insurance agencies. At a regional level, setting up structured collaboration with a rehabilitation center to finance a RTW program was cited. At a local level, teamwork between the administrative, medical and social departments of one agency was mentioned as facilitating.
Individuals (national health insurance physicians, case managers): barriers. Lack of knowledge of the relevant legislation and internal procedures of the national health insurance system was cited. The priority given to limiting health expenditure was also stressed, associated with mistrust of workers and other actors. Lack of time and overwork were unanimously identified as barriers.

Individuals: facilitators. Conversely, some individuals were identified as having good knowledge of the legislation and procedures to facilitate RTW, related to a professional role focusing on social support and work.

\section{Workplace system (table 4)}

External context: barriers. A competitive economic context, with restructuring and workforce reduction, was cited as a barrier to the feasibility of the Sherbrooke model.

External context: facilitators. Legally, the regulations concerning job accommodation for disabled workers and the prevention of occupational risk (French Employment Code) were mentioned. Good company relations with the occupational health and safety departments and national health insurances agencies (prevention department) were cited.

Workplace: barriers. At management level, fast managerial turnover, lack of latitude in decision-making and the fear of increasing costs and claims for better working conditions were cited as barriers. At the frontline management level, lack of communication between the manager and the team about RTW and lack of support to injured workers were highlighted. In work organization, production rates, workforce downsizing, use of temporary staff, failure to accommodate work posts and the priority given to other occupational risks were identified as possible barriers. In terms of social relations, a culture of contestation, with conflicts between branches of management and/or departments within a given establishment was mentioned as a barrier.

Workplace: facilitators. At management level, official commitments on RTW issues, with formalized procedures 


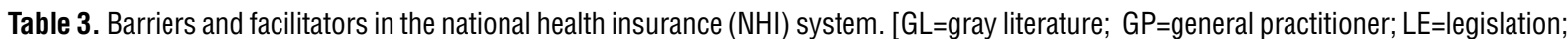
$\mathrm{OB}=$ observation; RTW=return to work; SV=stakeholder views.] Content in italic font refers to the data collected.

Level Barriers Facilitators

External: external context such as legal, economic or political context

Legal issues

Complexity of social legislation ( $\mathrm{LE}+\mathrm{SV}$ )

"People are lost, indeed, in all the tools and stakeholders of return to work. Make the difference, for example...the role of the different physicians, it's not always simple..." (NHI social worker)

Confidentiality of personal data (LE+SV)

"As far as sharing medical information was concerned, we were told to be very cautious." (NHI manager)

Legal priority given to primary prevention ( $\mathrm{LE}+\mathrm{SV})$

Occupational health legislation

Political issues

Conflicts between national health insurance agencies and medical private sector (GL)

National and medical press reports

Economic issues

Control of health expenditures (GL)

Reports of the National health insurance

Organizational: internal context of a regional or local health insurance agency

Target population and / or goal setting

Focus on patients on long term sick leave (SV+GL)

"As compared to early identification... we do it after 90 days of work absence... we are not early enough as compared to this model." (NHI manager)

Resources

Lack of human and financial resources to sustain work disability prevention measures and procedures $(\mathrm{SV}+\mathrm{GL})$

"You have a subvention, then you have a directive that says "networks are too expensive", then your budget is cut, everything crashes, it's extremely fragile." (Occupational Physician)

Fear of increasing rehabilitation expenses (SV)

"The health insurance system is extremely afraid of opening a Pandora's box with community health-care providers because, if you say "'ll give a doctor or a physiotherapist another case", then where do you stop?" (President of an occupational health service)

Limitations of the information system to identify the target population (SV)

"We know that early detection is paramount (...). But we didn't find our way for information exchanges." (NHI manager)

Collaborations Lack of collaboration within a given agency (medical and social departments) (SV)

Off record (NHI social worker)

\section{Individual: social insurance physician, case manager}

Knowledge

Values

Practice
Lack of knowledge about legislation and internal procedures (SV)

"We are not all at the same level. Each of us has some preferences. We work on that, for better practices." (NHI physician)

Focus on control and cost reduction (SV)

"Some people, they just want to cut the allocations. It's all that matters." (NHI social worker)

Lack of relational skills; negative interactions with workers; distrust (SV)

Off record (NHI social worker)

Work overload / Lack of time (SV)

"It seems to me that in our job as it is now it would mean a considerable work load ... Finally, it seems pretty heavy to me." (NHI physician)
Legislation pertaining to return to work (LE)

Social legislation

Social support of workers on long-term sick leave (SV+GL) National procedures of the health insurance

"... for us, the idea is for the person to rebuild their working life, not get stuck in extended sick leave and end up in depression." (NHI social worker)

Policy to identify the population at the subacute phase (SV+GL)

"It's part of our quality insurance process. We are ISO certified on the controls we do." (NHI physician)

Allocation of specific human and financial resources to develop work disability prevention measures and procedures $(\mathrm{SV}+\mathrm{GL})$

"The social worker is in the field, with the injured worker and the other stakeholders, to organize RTW." (NHI manager)

Structured collaboration on return to work issues between departments of a given agency $(\mathrm{OB}+\mathrm{GL})$

Internal procedures of a regional health insurance agency

Structured collaboration with a rehabilitation centre to fund a RTW program $(\mathrm{OB}+\mathrm{GL})$

"Lombaction" regional network

Accurate knowledge about legislation and internal procedures (SV)

"My approach is for the medical department not to be just a recorder of damage. But it has a more active role, or should have a more active role, being more incentive." (NHI physician) Focus on social and occupational support (SV+GL)

"We share some principles of this model (...): early, gradual and collaborative intervention, for return to work." (NHI manager) 
and ear-marked resources (job accommodation, extra temporary workers), were mentioned as possible facilitators. A perception of the Sherbrooke model as able to improve working conditions and corporate public image, reducing sick-leave duration and costs, was seen as a facilitator. The possibility of financing ergonomic intervention from outside budgets was mentioned as a possible facilitator. The personal involvement of the OP was underlined as a positive factor. In terms of social relations, the involvement of workers and unions in occupational health issues was underlined as a facilitator. At frontline management level, clear definition of roles and responsibilities in occupational health issues was considered positive.

Individuals (workers; colleagues; managers): barriers. The existence of interpersonal conflict with colleagues or managers was mentioned as a barrier, as was mutual mistrust. For managers, overwork, role conflict between production targets and occupational health and a lack of hierarchic support were possible barriers. With colleagues, overwork and skepticism about medical problems could induce hostility and rejection. For workers with LBP, the feeling of being judged and having to justify absence, pain and limitations was perceived as a barrier.

Individuals: facilitators. Conversely, collaboration with colleagues and superiors and mutual trust were underlined as facilitators. Qualities of leadership such as problem solving, and relationship capabilities such as empathy and support were mentioned. The perceived benefit of the Sherbrooke model, recognition by the employer of the consequences of job changes, and the inclusion of occupational health indicators in management assessment were cited positively.

\section{Discussion}

The present results confirm the variety of barriers to implementation of RTW interventions, in agreement with other literature reports $(7,18-21)$. The notable feature of the study is the ability of the conceptual framework (14) to identify barriers ahead of implementation. This confirms the special attention which needs to be paid when implementing this type of program, to avoid the repeated failures previously reported (7).

\section{Implementation science}

Implementation science has been the focus of many studies, to the point of leading to a certain confusion of definitions and theoretical frameworks $(22,23)$. Some authors have sought to bring these together in integra- tive frameworks and clarify the concepts used $(9,10,22$, 23). Despite the efficacy of implementation strategies adapted to identified barriers (11), it remains unknown which implementation interventions are most effective, in what context, with what mechanisms and means of administration (23).

\section{Implementation strategies adapted to identified barriers}

The present results have two important consequences for implementation. The existence of barriers in each category of agent suggests that implementation interventions limited to one particular category have little chance of success. Rather, an inter-sector strategy, associating healthcare, health insurance and the workplace, should be adopted. The existence of barriers at each level suggests that implementation interventions limited to one particular level (external context, organizations, or individuals) have less chance of success than a strategy aimed at changes at different levels. Given the number of barriers identified, they need ranking in terms of importance and ease of change. A pragmatic approach would be to consider first of all barriers common to the different categories of agent.

A change in the law to overcome medical and healthdata confidentiality may not be realistic. However, these barriers can be overcome by reminding those concerned that the French law allows the sharing of information for multidisciplinary patient management, in the interest and with the consent of the patient. Thus this barrier is to be got around not by legislation so much as by changing representations and through professional collaboration. A strategy to deal with the complexity of the legal framework could be founded on ongoing training with information supports shared by the different types of agent, including the low-back pain sufferers themselves.

The perceived legal risk could be changed by better knowledge and perception of the benefits of the Sherbrooke model. Implementation interventions should thus include well thought-out information on benefits according to category of agent. One strategy would be to develop the Sherbrooke model progressively on a limited basis in a few volunteer firms, so as to test out implementation in a favorable environment, thus visibly demonstrating its feasibility and benefits to other agents. Lack of human and financial resources is obviously a common barrier needing to be overcome; a solution would consist of training and financing resource persons such as "case managers" or "RTW coordinators". These agents certainly constitute one of the active ingredients of the Sherbrooke model (3). Their skills have been described in the literature (24) and are presently lacking in the French health system on a large scale.

At the individual level, common barriers were personal overwork (lack of time), lack of trust between 
Table 4. Barriers and facilitators in the workplace system. [GL=gray literative; GP=general practitioner; $L E=$ legislation; $O B=0 b s e r v a t i o n ;$ RTW=return to work; SV=stakeholder views.] Content in italic font refers to the data collected.

\begin{tabular}{ll}
\hline Level & Barriers \\
\hline External (external context) & \\
& Economic competition; restructuring, downsizing \\
& $(\mathrm{SV}+\mathrm{GL})$ \\
& "... You have to realize that we have a deficit of 20 \\
& million in our budget, which explains why we find it \\
& difficult to have extra staff at certain work-posts." (Human \\
& resources department manager, University Hospital)
\end{tabular}

\section{Workplace (internal context)}

Top management

Frontline management

Work organization

Social relations

Individual (worker, co-workers, managers)

Inter-personal conflicts (between colleagues or with the hierarchy); mutual distrust; lack of time to get involved (SV)

"On the difficulty of finding suitable jobs, our basic dif-

Systematic policy of non-reporting and / or contesting workers' accident claims (SV)

"Let me tell you one thing: the workers have back pain, because of work. Until you discover that, on Sundays, they work on the roof of their house." (Employer)

Cost-containment policies (SV+GL)

"It's hard to link with the workplaces, mainly because of financial problems. That's what we must work on." (Occupational physician, regional labor inspectorate) Fear of increasing social demands, complications and costs (SV) Lack of communication and supportive management in the RTW process

"My role stops here. Later, if they \{the workers\} want to I let them regulate themselves." (Frontline manager)

Physical risk factors of musculoskeletal disorders (SV) "What causes back pain? ... It's working conditions ... to produce. Oh yes, every year you have to have productivity." (Employee, union representative, car-maker) Lack of workplace accommodation (SV)

"Most of the time, our problem is the lack of improvement of the workstation."(Physiotherapist)

Priority to other occupational hazards $(\mathrm{SV}+\mathrm{GL})$

Chemical risk reduction plan ranked as the highest priority lack of participation of workers and unions (SV) union representative, car-maker)

Conflicts between managers or departments within the workplace (SV) are so assertive... they don't have a clue about human factors." (Occupational physician)
Facilitators

Good relations with external agencies $(\mathrm{OB}+\mathrm{GL})$

"Lombaction" regional network

Rules and regulations (work accommodation) (LE)

Social and occupational health legislation

Formal commitment and support in RTW; formalized RTW policy and procedures (SV)

"... the way you treat the most fragile is after all a strong symbol ficulty ... is that we often don't have the time to analyze our work-posts properly." (Staff social worker, car-maker)

Resources such as organizational and ergonomic training, extratime and / or money (SV+OB)

"The employers also hesitate to get the workers back to work, because it can damage their back." (NHI physician) fix who's done something or not, I mean, it's teamwork, and also productivity. More it goes on, more you've got

Poor social dialogue; culture of resistance and conflicts;

"In the other plant, war is declared to the Union. So the director divided the people...to better reign." (Employee,

"There are engineers in the department of methods, they
Inter-personal collaborations; mutual confidence; personal awareness of ergonomics (SV)
"Finally, if you can try and speed up return to work and restrict sick leave, obviously l'm interested. On a purely economic level. Like, it's more or less logical." (CEO, car-maker)

"Well, I think with the unions, there'll be no problem. Because it's to help employees get back into the company." (Employee, union representative, car-maker)

Collaboration between services (SV)

"We developed a planning... according to the situation, in fact. We organize the work...in the short and medium-term, it's possible." (Human resource manager)

Capacity for collective action among workers; effective social dialogue; involvement of workers and unions (SV)

"If he \{the production manager\} wants a good social climate, he has to make compromises, as we do. If there is a problem with a worker, he comes to us before. Sometimes, we can fix the problem without the worker being convoked. Yes, any problem." (Employee, union representative, car-maker) 
Table 4. Continued

\begin{tabular}{|c|c|c|}
\hline Level & Barriers & Facilitators \\
\hline & $\begin{array}{l}\text { "The current culture between the employees and the em- } \\
\text { ployers, it doesn't allow (...) to get back in the } \\
\text { workplace." (NHI physician) }\end{array}$ & $\begin{array}{l}\text { "The workplace may be very facilitating. All the employers are } \\
\text { not keen to lay off the injured workers." (NHI social worker) }\end{array}$ \\
\hline \multirow[t]{2}{*}{ Managers } & $\begin{array}{l}\text { Personal work overload incurred by the RTW process } \\
\text { and work accommodation; role conflict between } \\
\text { production and health and safety requirements; absent } \\
\text { and/ or non-supportive manager (SV) }\end{array}$ & $\begin{array}{l}\text { Leadership qualities such as problem solving, contact making, } \\
\text { empathy, support; recognition by the employer of the conse- } \\
\text { quences of modified work; integration of OHS indicators in the } \\
\text { manager's evaluation (SV) }\end{array}$ \\
\hline & $\begin{array}{l}\text { "So, this worker won't perform such tasks due to ill } \\
\text { health... provoking conflicts with the colleagues: "He } \\
\text { doesn't do the job because of his back, and nobody } \\
\text { cares for us... for us, it's OK?" You see, it's complex ... } \\
\text { it's daily." (Frontline manager) }\end{array}$ & $\begin{array}{l}\text { "And a resource I think's quite important is the frontline manag- } \\
\text { ers in the departments, who after all know the employees very } \\
\text { well." (Personnel occupational psychologist, University Hospital) }\end{array}$ \\
\hline \multirow[t]{2}{*}{ Co-workers } & $\begin{array}{l}\text { Resentment and hostility between co-workers; personal } \\
\text { work overload incurred by the RTW process and work } \\
\text { accommodation (SV) }\end{array}$ & \\
\hline & $\begin{array}{l}\text { "The hazing can come from other workers, against the } \\
\text { guy you're trying to help ... Being picked on by your own } \\
\text { workmates, there's nothing worse." (Employee, union } \\
\text { representative, car-maker) }\end{array}$ & \\
\hline \multirow[t]{2}{*}{ Workers (returning to work) } & $\begin{array}{l}\text { Feeling judged and obliged to justify their previous } \\
\text { absence, pain, disability and RTW efforts (SV) }\end{array}$ & Being reassured while performing job tasks (SV) \\
\hline & $\begin{array}{l}\text { "Coming back in the workplace, being exposed with one's } \\
\text { frailty, it's not simple...it's not easy." (NIH social worker) }\end{array}$ & $\begin{array}{l}\text { "Once you've understood your body can endure it, then you keep } \\
\text { on." (Injured worker) }\end{array}$ \\
\hline
\end{tabular}

other agents, and individualistic professional practices. The first of these could be overcome by case managers taking some of the workload from the other agents. Mistrust can also be overcome by a communication campaign targeting the shared benefits of the Sherbrooke model and visible pilots demonstrating its benefit. There is no easy solution to the problem of individualistic professional practices, but it may be hoped that the above solutions will have some impact here too.

Barriers specific to healthcare professionals (overmedicalization and over-functional approach) require improved link-up between first-line care and rehabilitation and occupational medicine. This could be achieved by in-service medical training and health networks. Barriers specific to the workplace require dialog on RTW for employees with health problems; this could involve interventions specifically targeting certain occupational sectors.

\section{Strong and weak points of the study}

The multiple case study design (15) allowed a complex notion to be dealt with in a real life setting. Several measures were taken to ensure the validity of the results (16). Drawing up an eclectic conceptual framework allowed barriers and facilitators to be identified in the various agents and at the various levels. Triangulation of data collection and investigators at the time of analysis was performed. The investigators' interpretation of the results was fed back to the participants. Use of a single database and software package ensured process traceability. Analytical categories were saturated at the end of the analysis. A log-book kept during data collection enabled results to be contextualized and investigator subjectivity to be included. For all these reasons, the results can be presumed to have good construct validity and reliability.

The study also involved several limitations. The maximum number of study cases was originally chosen for logistic reasons. Although including extra cases might have identified other results, the saturation observed at end of analysis suggests otherwise. Workplace sampling led to over-representation of the healthcare sector. However, input from two occupational health services (15 OP) allowed experience to be included from a broad economic sector. Involving GP in the study was very difficult - which is in itself an interesting finding, reflecting the difficulty of getting these agents to participate in this kind of project. Only one disabled worker and two co-workers could be interviewed in the participating workplaces. This limitation is partially compensated by the accounts of injured workers in the voice of other respondents (social workers, occupational physicians).

\section{Generalizability of the results}

The barriers and facilitators identified in this study, although identified in the French context, are believed to apply in other countries. The occupational health and safety legislation presents common features in many European countries. Issues identified within the (occupational) health system, in the workplace and within the insurance system have been reported in several other 
countries $(18-21,25,26)$.

\section{Future research}

The next stages will consist of discussing the implementation strategy drawn up here between the stakeholders and implementation scientists, applying this strategy and monitoring the process and results of implementation. The effects of the Sherbrooke model should not be assessed until implementation is such as to guarantee its lasting and routine use. Only then can effectiveness at a population level be established for this new intervention to be integrated into healthcare provisions, in contrast to an experimental trial in a controlled context.

\section{Concluding remarks}

Facilitating RTW for low-back pain sufferers requires several barriers to be overcome among healthcare professionals, workplaces and the health insurance system. Implementing a RTW intervention should be considered as a process at high risk of failure, requiring a strategy painstakingly adapted to the barriers and facilitators identified in the field. Such strategies are presently drawn up in a more pragmatic than scientific manner. Implementation process assessment is essential to guarantee that the implemented intervention is sustainable before attempting to assess its effectiveness.

\section{Acknowledgments}

Jean-Baptiste Fassier was supported as a PhD student at the time of the study by two personal grants received from the Chaire en Réadaptation au Travail JacquesArmand Bombardier and Pratt \& Whitney Canada, and from the Charles LeMoyne Hospital Research Centre, Longueuil, Quebec, Canada.

Part of this work was supported by a grant received from the French occupational risk department of the national health insurance Caisse Nationale d'Assurance Maladie des Travailleurs Salariés, Direction des risques professionnels (CNAMTS).

The author is grateful to the persons who participated in the study and to the personnel of the CAPRIT, School of Rehabilitation, Université de Sherbrooke.

\section{References}

1. Haukka E, Kaila-Kangas L, Ojajarvi A, Miranda H, Karppinen J, Viikari-Juntura E, et al. Pain in multiple sites and sickness absence trajectories: a prospective study among Finns. Pain. 2012;2:306-12.

2. van Oostrom SH, Driessen MT, de Vet HCW, Franche RL, Schonstein E, Loisel P, et al. Workplace interventions for preventing work disability. Cochrane Database Syst Rev. 2009; Issue 2:Art. No.: CD006955.

3. Loisel P, Abenhaim L, Durand P, Esdaile JM, Suissa S, Gosselin L, et al. A population-based, randomized clinical trial on back pain management. Spine. 1997;24:2911-8. http:// dx.doi.org/10.1097/00007632-199712150-00014.

4. Durand MJ, Loisel P. Therapeutic return to work: rehabilitation in the workplace. Work. 2001;1:57-63.

5. Loisel P, Lemaire J, Poitras S, Durand MJ, Champagne F, Stock S, et al. Cost-benefit and cost-effectiveness analysis of a disability prevention model for back pain management: a six year follow up study. Occup Environ Med. 2002;12:807-15. http://dx.doi.org/10.1136/oem.59.12.807.

6. Loisel P, Durand MJ, Diallo B, Vachon B, Charpentier N, Labelle J. From evidence to community practice in work rehabilitation: The Quebec experience. Clin J Pain. 2003;2:105-13. http://dx.doi.org/10.1097/00002508200303000-00005.

7. Loisel P, Buchbinder R, Hazard R, Keller R, Scheel I, van Tulder M, et al. Prevention of Work Disability Due to Musculoskeletal Disorders: The Challenge of Implementing Evidence. J Occup Rehabil. 2005;4:507-24. http://dx.doi. org/10.1007/s10926-005-8031-2.

8. Craig P, Dieppe P, Macintyre S, Mitchie S, Nazareth I, Petticrew M. Developing and evaluating complex interventions: the new Medical Research Council guidance. BMJ. 2008;7676: 979-83.

9. Damschroder L, Aron D, Keith R, Kirsh S, Alexander J, Lowery J. Fostering implementation of health services research findings into practice: a consolidated framework for advancing implementation science. Implement Sci. 2009;1:50. http://dx.doi.org/10.1186/1748-5908-4-50.

10. Greenhalgh T, Robert G, MacFarlane F, Bate P, Kyriakidou O. Diffusion of Innovations in Service Organizations: Systematic Review and Recommendations. Milbank Q. 2004;4:581-635. http://dx.doi.org/10.1111/j.0887-378X.2004.00325.x.

11. Baker R, Camosso-Stefinovic J, Gillies C, Shaw EJ, Cheater F, Flottorp S, et al. Tailored interventions to overcome identified barriers to change: effects on professional practice and health care outcomes [Systematic Review]. Cochrane Database Syst Rev. 2010;(3).

12. Abenhaim L, Rossignol M, Valat JP, Nordin M, Avouac B, Blotman F, et al. The role of activity in the therapeutic management of back pain. Report of the International Paris Task Force on Back Pain. Spine. 2000;4 Suppl:1S-33S. http:// dx.doi.org/10.1097/00007632-200002151-00001.

13. Poiraudeau S. Implication des acteurs médicaux et non médicaux du monde du travail dans la prise en charge du lombalgique chronique : un élément primordial pour la reprise des activités professionnelles? [Should companies employees, managers and doctors be associated in functional restoration programs?]. Ann Readapt Med Phys. 2004;8:573-4. http:// 
dx.doi.org/10.1016/j.annrmp.2004.08.001.

14. Fassier JB, Durand MJ, Loisel P. 2nd place, PREMUS best paper competition: implementing return-to-work interventions for workers with low-back pain - a conceptual framework to identify barriers and facilitators. Scand J Work Environ Health. 2011;2:99-108. http://dx.doi.org/10.5271/sjweh.3138.

15. Yin RK. Case Study Research : Design and Methods. 3rd ed. Applied Social Research Methods Series, ed. R.K. Yin. Thousand Oaks, CA: Sage; 2003.

16. Yin RK. Enhancing the quality of case studies in health services research. Health Serv Res. 1999;5 Pt 2: 1209-24.

17. Sadler DR. Evaluation, Policy Analysis, and Multiple Case Studies: Aspects of Focus and Sampling. Educ Eval Policy Anal. 1985;2:143-9. http://dx.doi. org/10.3102/01623737007002143.

18. MacEachen E, Kosny A, Ferrier S, Chambers L. The «Toxic Dose» of System Problems: Why Some Injured Workers Don't Return to Work as Expected. J Occup Rehabil. 2010;3:349-66. http://dx.doi.org/10.1007/s10926-010-9229-5.

19. Tjulin A, Edvardsson Stiwne E, Ekberg K. Experience of the implementation of a multi-stakeholder return-to-work programme. J Occup Rehabil. 2009;4:409-18. http://dx.doi. org/10.1007/s10926-009-9195-y.

20. Ståhl C, Svensson T, Petersson G, Ekberg K. A Matter of Trust? A Study of Coordination of Swedish Stakeholders in Returnto-Work. J Occup Rehabil. 2010;3:299-310. http://dx.doi. org/10.1007/s10926-009-9205-0.

21. Maiwald K, de Rijk A, Guzman J, Schonstein E, Yassi A. Evaluation of a workplace disability prevention intervention in Canada: examining differing perceptions of stakeholders. J Occup Rehabil. 2011;2:179-89. http://dx.doi.org/10.1007/ s10926-010-9267-z.

22. Graham ID, Logan J, Harrison MB, Straus SE, Tetroe J, Caswell W, et al. Lost In Knowledge Translation: Time For A Map? J Contin Educ Health Prof. 2006;1.

23. Colquhoun H, Leeman J, Michie S, Lokker C, Bragge P, Hempel S, et al. Towards a common terminology: a simplified framework of interventions to promote and integrate evidence into health practices, systems, and policies. Implement Sci. 2014;1:51. http://dx.doi.org/10.1186/1748-5908-9-51.

24. Shaw W, Hong Q-n, Pransky G, Loisel P. A Literature Review Describing the Role of Return-to-Work Coordinators in Trial Programs and Interventions Designed to Prevent Workplace Disability. J Occup Rehabil. 2008;1:2-15. http://dx.doi. org/10.1007/s10926-007-9115-y.

25. Stahl C, Svensson T, Ekberg K, Stahl C, Svensson T, Ekberg K. From cooperation to conflict? Swedish rehabilitation professionals' experiences of interorganizational cooperation. J Occup Rehabil. 2011;3:441-8. http://dx.doi.org/10.1007/ s10926-010-9281-1.

26. van der Molen HF, Sluiter JK, Hulshof CT, Vink P, van Duivenbooden C, Holman R, et al. Implementation of participatory ergonomics intervention in construction companies. Scand J Work Environ Health. 2005;3: 191-204. http://dx.doi.org/10.5271/sjweh.869.

Received for publication: 8 December 2014 